\title{
Dynamical mechanisms controlling the vertical redistribution of dust and the thermodynamic structure of the West Saharan atmospheric boundary layer during summer
}

\author{
Juan Cuesta, ${ }^{1,2 *}$ John H. Marsham, ${ }^{2}$ Douglas J. Parker ${ }^{2}$ and Cyrille Flamant ${ }^{3}$ \\ 'Laboratoire de Météorologie Dynamique/Institut Pierre Simon Laplace, École Polytechnique, 9 I I 28 Palaiseau, France \\ ${ }^{2}$ School of Earth and Environment, University of Leeds, Leeds, LS2 9JT, UK \\ ${ }^{3}$ Service d'Aéronomie/Institut Pierre Simon Laplace, 4 Place Jussieu, 75252 Paris, France
}

* Correspondence to:

Juan Cuesta, Laboratoire de

Météorologie Dynamique/lnstitut

Pierre Simon Laplace, École

Polytechnique, 91 I 28 Palaiseau,

France.

E-mail:

cuesta@lmd.polytechnique.fr

Received: 5 August 2008

Revised: 17 November 2008

Accepted: 18 November 2008

\begin{abstract}
The Saharan atmospheric boundary layer (SABL) plays a significant role in the atmospheric global circulation and directly affects the vertical redistribution of dust originated in the Sahara, the world's largest dust source. Recent measurements have revealed a variety of new dynamical mechanisms that control the structure of the SABL, which are responsible for exchange between the Saharan convective and residual boundary layers. Using new spaceborne laser remote sensing data (CALIPSO) and recently published results, we provide an overview of the following known dynamical mechanisms: diurnal vertical mixing, dynamical lifting (density currents and cold air outbreaks) and topographic effects (mountains and albedo anomalies). Copyright (c) 2009 Royal Meteorological Society
\end{abstract}

Keywords: West African monsoon; harmattan; AMMA; GERBILS; SAMUM; CALIPSO

\section{Background}

The Sahara is the world's largest desert, and the characteristics of the atmosphere in this region play a significant role in the atmospheric global circulation. Apart from its direct thermodynamic role in the atmosphere, the Sahara is the world's most significant source of mineral dust in the atmosphere (Tanaka and Chiba, 2006). Various mechanisms are known to lead to high wind speed events in the Sahara and so significant dust uplift. In many regions the downward mixing of momentum from the nocturnal low-level jet, as boundary-layer convection develops during the morning, results in significant dust uplift over wide areas such as the Bodélé depression (Washington et al., 2006) or the western Sahara (Knippertz, 2008; Knippertz et al., 2008). In addition, winds from the boundary-layer convection itself can enhance dust uplift (Cakmur et al., 2004; Marsham et al., 2008b). A diurnal cycle of dust load has been reported near the Sahelian and Saharan source regions (N'Tchayi Mbourou et al., 1997; Engelstaedter et al., 2006; Chaboureau et al., 2007), which is a result of daytime boundary-layer convection removing the nocturnal inversion, and affecting dust uplift and transport. Dust devils, which form in convective boundary layers with sheared but relatively light winds, may also be important in some regions (Koch and Renno, 2005). Dust uplift by density currents is also important in many locations (Sterk, 2002; Flamant et al., 2007 hereafter F07; Knippertz et al., 2007; Bou Karam et al., 2008; Marsham et al., 2008b). After uplift, very coarse particles (with diameter $d>30 \mu \mathrm{m}$ ) settle down quickly in the proximity of the sources. Lighter Saharan dust particles $(d<10 \mu \mathrm{m})$ can travel large distances around the globe (Shao, 2000). While being transported, dust concentration decreases progressively by dry deposition and away from the Sahara also by scavenging and washout due to precipitation (Shao, 2000).

Over the Sahara, dust is transported by dry convection and it is mostly located in the Saharan atmospheric boundary layer (SABL), which is up to $6 \mathrm{~km}$ deep (Gamo, 1996). Three typical situations have been observed: freshly uplifted dust with clearer air above (e.g. Marsham et al., 2008b), dust concentrated in an elevated layer within the SABL with clearer air underneath (e.g. F07), or dust profiles which are wellmixed down to the ground, as consistently observed in the Hoggar region (Algeria; Cuesta et al., 2008, hereafter C08). Sometimes more complex layering occurs within a stratified layer in the SABL [i.e. within the Saharan residual layer or (SRL)]. Moreover, when Saharan dust is transported beyond the Sahara, and particularly in the summertime, it typically rises over the cooler and moist air encountered near the surface and forms an elevated layer (Reid et al., 2002; F07). Over the Atlantic this layer has been termed the Saharan air layer [(SAL); Karyampudi and Carlson, 1988].

In this paper, we refer to the whole depth of the boundary layer over the Sahara as the SABL, which during the day encompasses the Saharan convective 


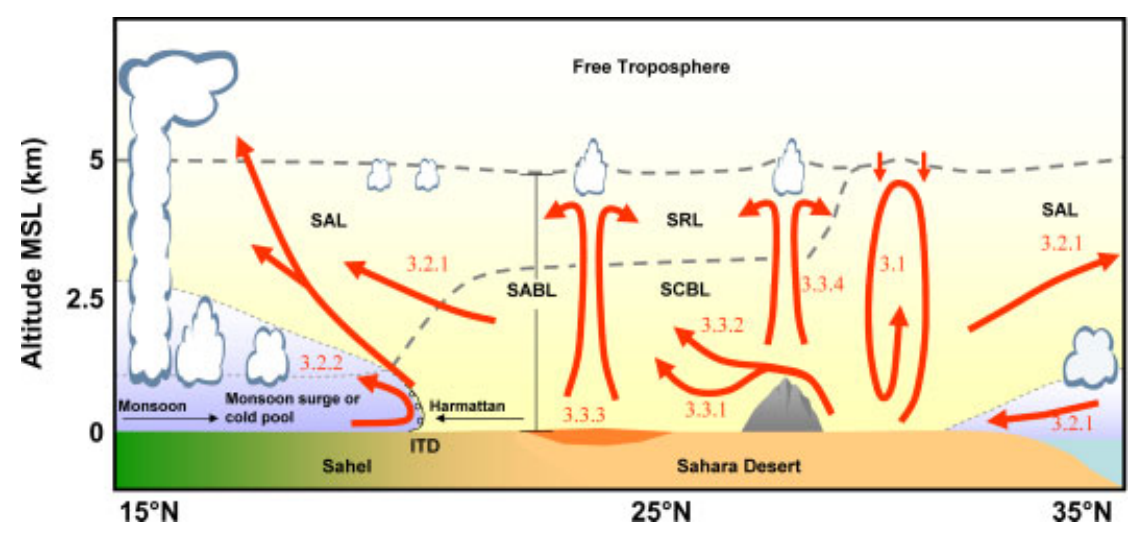

Figure I. Schematic of the mechanisms (red arrows) which control the SABL structure and dust vertical redistribution (labels refer to Section numbers): 3.I: Diurnal vertical mixing, 3.2: Dynamical lifting (upgliding, gravity currents and cold air outbreaks) and 3.3: Topographic effects (mountains and albedo anomalies). Shading (yellow or light blue) indicates air masses origin (i.e. from the SABL, Gulf of Guinea or mid-latitudes) and temperature. This representation does not correspond to any day nor suggest that the $\mathrm{SABL}$ is more likely to be well-mixed in the north than the south. Commonly, the SABL state is mostly horizontally homogeneous.

boundary layer (SCBL) and the SRL (Figure 1). It has been observed (Parker et al., 2005b; F07) that the SABL is not always fully well mixed around midday, as might be expected of a near-neutral boundary layer over a hot surface during daytime. It appears that until the early afternoon the SABL often consists of a SRL, into which a SCBL is growing. Indeed, lidar observations of the SABL diurnal cycle in the Hoggar showed that it typically reaches its maximum depth only in the late afternoon (from $\sim 1600$ UTC to $\sim 1800$ UTC in the summer season; C08). Radiative effects of dust and water vapor may contribute to the stabilization of the SRL, slowing down the SCBL development: however, the role of the radiative properties of dust in stabilizing desert boundary layers is not fully understood.

The objective of this paper is to give an overview of recent advances concerning the main dynamical mechanisms which control the structure of the SABL and which affect the vertical redistribution of dust within it (Figure 1). We cite previous works and, using recently available laser remote sensing data, provide examples that illustrate likely occurrences of the highlighted mechanisms. They are described considering dust aerosols as tracers of the atmospheric dynamics while interpreting the space-borne lidar data. From this we propose some priorities for analysis in coming years.

\section{Datasets}

Information about the structure of dust layers over the Sahara is provided by the space-borne lidar onboard the CALIPSO (Cloud-Aerosol Lidar and Infrared Pathfinder Satellite Observation; Winker et al., 2007) satellite. Following Fernald et al. (1972) and Young et al. (2008), the CALIPSO lidar attenuated backscatter profiles $\beta T^{2}$ (level 1 data) are processed in order to correct for atmospheric transmission, $T^{2}$, and obtain $\beta$. To do so, we consider a particle backscatterto-extinction ratio of $0.024 \mathrm{sr}^{-1}$, representative of dust particles (Cattrall et al., 2005), which is modulated in the vertical by a multiple scattering coefficient, $\eta$, according to the Monte Carlo simulations in Young et al. (2008). The horizontal structure and temporal variability of dust plumes is qualitatively described using observations from spinning enhanced visible and infra red imager [(SEVIRI), with 15 min temporal resolution] onboard Meteosat Second Generation (MSG) via false-color images (available on http://loaamma.univ-lille1.fr/AMMA/). European Centre for Medium-range Weather Forecasts (ECMWF) analyses are used with $0.5^{\circ}$ resolution.

\section{Mechanisms}

\section{I. Diurnal mixing throughout the SABL}

The 'textbook' behavior of a SCBL occurs when the SCBL fully erodes the SRL by the end of the daylight hours, over a large area (much larger than the scales of convective eddies, and of topographic features). Ground-based lidar and radiosonde observations from the African monsoon multidisciplinary analysis (AMMA) and Saharan mineral dust experiment (SAMUM) field campaigns consistently show this to occur close to the Hoggar and Atlas massifs on many days (e.g. C08; Knippertz et al., 2008). Figure 2(a) shows a case in which the SABL is wellmixed throughout its depth over a large spatial domain. From 23 to $34^{\circ} \mathrm{N}$, the potential temperatures from the ECMWF model and radiosoundings (at 1200 UTC) as well as the measurements from the space-borne lidar (at 1307 UTC) all indicate a well-mixed state from the surface to the inversion, at about $5.5 \mathrm{~km}$ above mean sea level $(\mathrm{msl})$. Lidar profiles north of $18^{\circ} \mathrm{N}$ show a rather moderate dust load up to $\sim 5.5 \mathrm{~km} \mathrm{msl}$ $\left(\beta>1.510^{-3} \mathrm{~km}^{-1} \mathrm{sr}^{-1}\right)$. From 13.5 to $16^{\circ} \mathrm{N}$, relatively high aerosol loadings are mostly confined to the SCBL (with its top between $\sim 2.5$ and $\sim 3.5 \mathrm{~km} \mathrm{msl}$ ), while lower aerosol contents are observed in the more stably stratified layers above. 
(a)
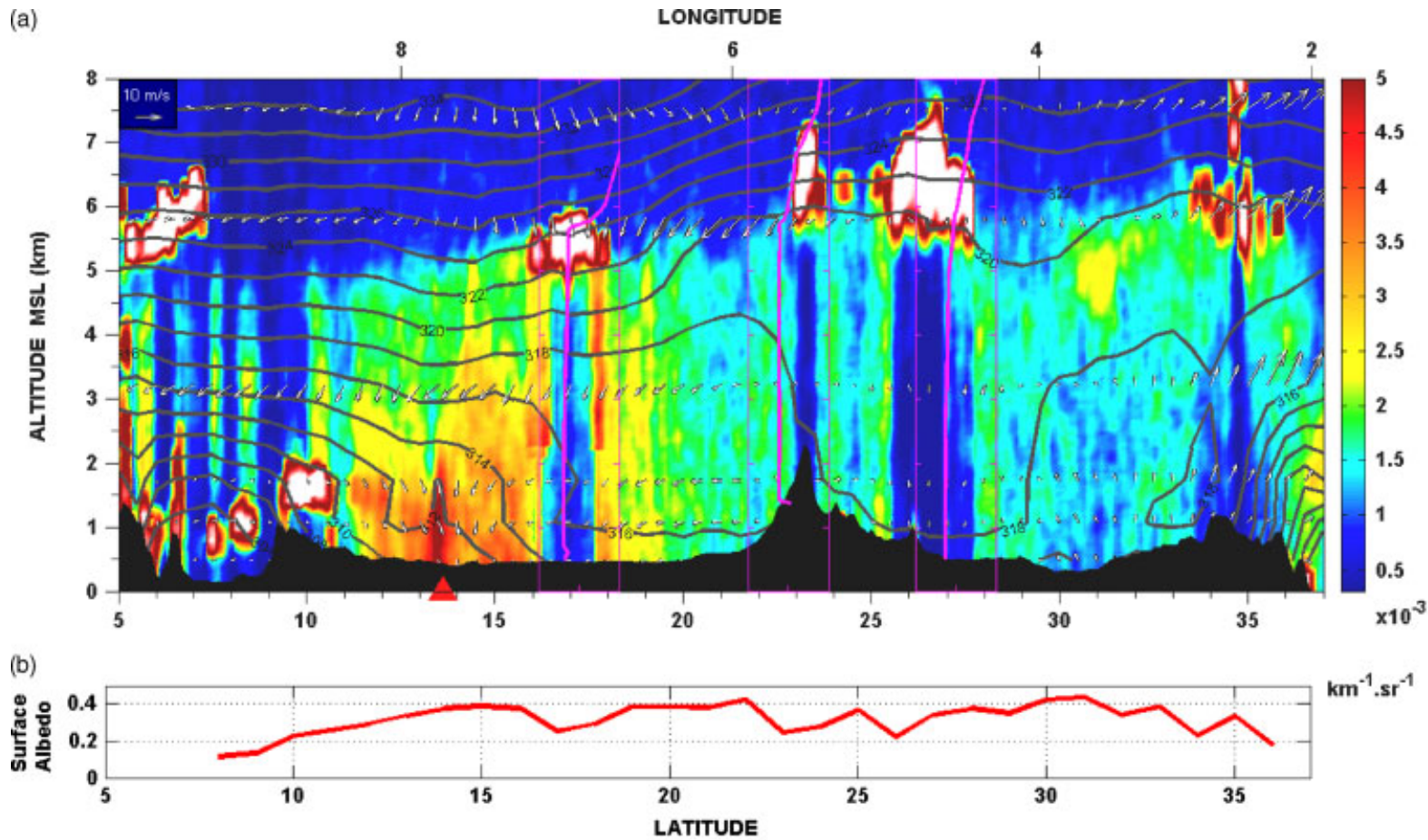

(c)

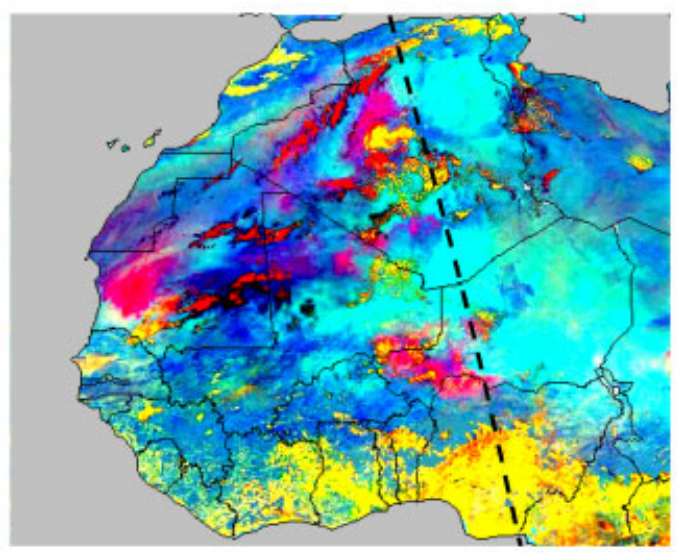

(d)

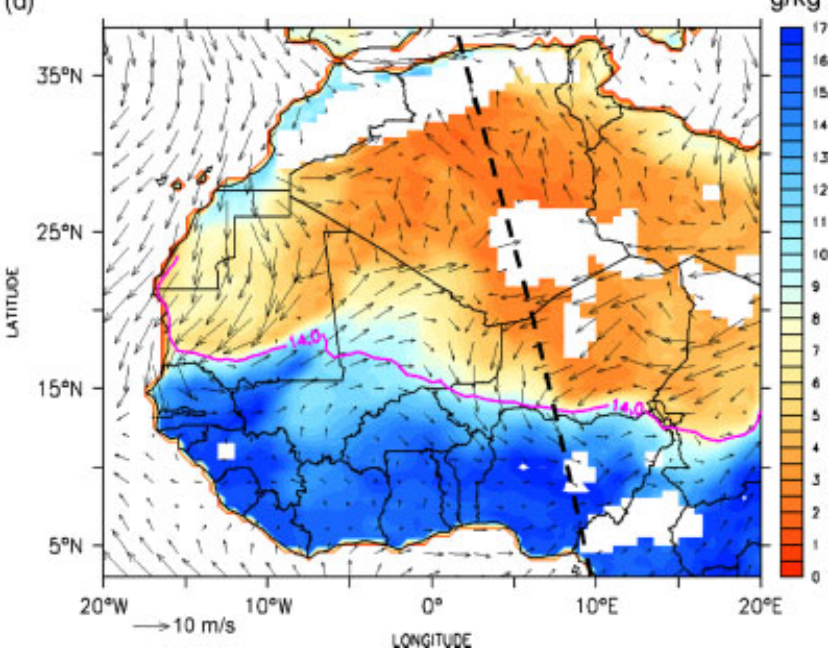

Figure 2. (a) CALIPSO lidar transect over West Africa on the 25 June 2006 at 1307 UTC: backscatter coefficient profiles at $532 \mathrm{~nm}$ with a $60 \mathrm{~m}(12 \mathrm{~km})$ resolution in the vertical (horizontal). The outline of the topography appears in black. Dense clouds appear in white, the low backscatter values below them being due to lidar signal extinction. Superimposed on the CALIPSO lidar data are: (i) I 200 UTC ECMWF analyses of horizontal winds (arrows), potential temperature (dark gray plain contours) and the location of the ITD (marked as a red triangle, derived using the $14^{\circ} \mathrm{C}$ dew point temperature criterion) and (ii) virtual temperature radiosonde profiles in pink (from 310 to $330 \mathrm{~K}$ on the horizontal axes) at Agadez $\left(17^{\circ} \mathrm{N} 8^{\circ} \mathrm{E}\right.$ ), Tamanrasset $\left(22.8^{\circ} \mathrm{N} 5.5^{\circ} \mathrm{E}\right)$ and In Salah $\left(27.2^{\circ} \mathrm{N} 2.5^{\circ} \mathrm{E}\right)$. (b) Surface albedo retrieved from MODIS along the CALIPSO track. (c) SEVIRI-derived false color images over West Africa at I330 UTC, identifying dust (purple/red), clouds (orange/yellow) and differences in surface emissivity retrieved in absence of dust or clouds (green/magenta). The dashed black line is the CALIPSO track. (d) ECMWF I200 UTC analysis of wind and water vapor mixing ratio at $925 \mathrm{hPa}$ and the contour of near surface $14^{\circ} \mathrm{C}$ dew point temperature marking the position of the ITD.

When the SCBL is well mixed throughout the depth of the SABL it can entrain air from the free troposphere (FT) above, with stronger inversions at the top of the SCBL yielding lower entrainment rates (e.g. Parker, 2002). Air from regions surrounding the Sahara may also move isentropically into the SRL, particularly at night and in the morning, and can then be entrained and mixed into the SCBL (e.g. Parker et al., 2005b). These mechanisms imply a reduction in the concentration of dust due to dilution below the
SABL top. The dry convection also creates a limitation on the use of trajectory analysis in the SABL during the afternoon (Knippertz et al., 2008).

\subsection{Dynamical lifting of air into the SRL}

\subsubsection{Cold air intrusions and slantwise advection}

In addition to sometimes leading to deep convection and cold-pool outflows (Section 3.2.2; Knippertz 
and Fink, 2006), cold air fronts associated with midlatitude troughs can induce low-level intrusions of clean and cold air into the northern Sahara. Likewise, in the southern Sahara the cooler moist monsoon air is often observed to undercut the SABL during summer. Figure 3(a) shows an example in which the SABL, even at 1332 UTC on a day in late June, is very far from being well-mixed. The situation is characterized by two streams of cold air advection at low levels which induces the presence of slanted isentropes in the boundaries with the SABL (Figure $3\left(\mathrm{a}\right.$ ) around $14^{\circ} \mathrm{N}$ and $22^{\circ} \mathrm{N}$ and up to $\sim 3 \mathrm{~km}$ $\mathrm{msl}$. The monsoon flow from the south is bringing cool air as far north as $17^{\circ} \mathrm{N}$, while a northwesterly outbreak of cold air from the Atlantic has penetrated inland to $21^{\circ} \mathrm{N}$ (Figure 3(c)). The incoming low-level cool airflows are characterized by low dust loadings. The zone between these flows, from $17^{\circ} \mathrm{N}$ to $21^{\circ} \mathrm{N}$, is weakly stratified at low levels, with a deep low-stability SRL from around 2 to $5 \mathrm{~km}$ and moderate dust loadings. The SRL appears to be advected following the slanted isentropes above the incoming cold air, leading to an elevated wedge of high aerosol to the north $\left(27^{\circ} \mathrm{N}\right)$ and south $\left(6^{\circ} \mathrm{N}\right)$ of the surface thermal maximum. ECMWF winds at $700 \mathrm{hPa}$ (Figure 3(b)) show northward (southward) advection of the northern (southern) dust wing a few degrees east (west) from the CALIPSO track. SEVIRI plot (Figure 3(b)) shows clearer air coming from the Atlantic and only moderate dust loading (pale magenta colors) associated with the plume detected by CALIPSO.

Slantwise advection occurs in a region with slanted isentropes and under conditions of near-adiabatic flow.

(a) LONGITUDE

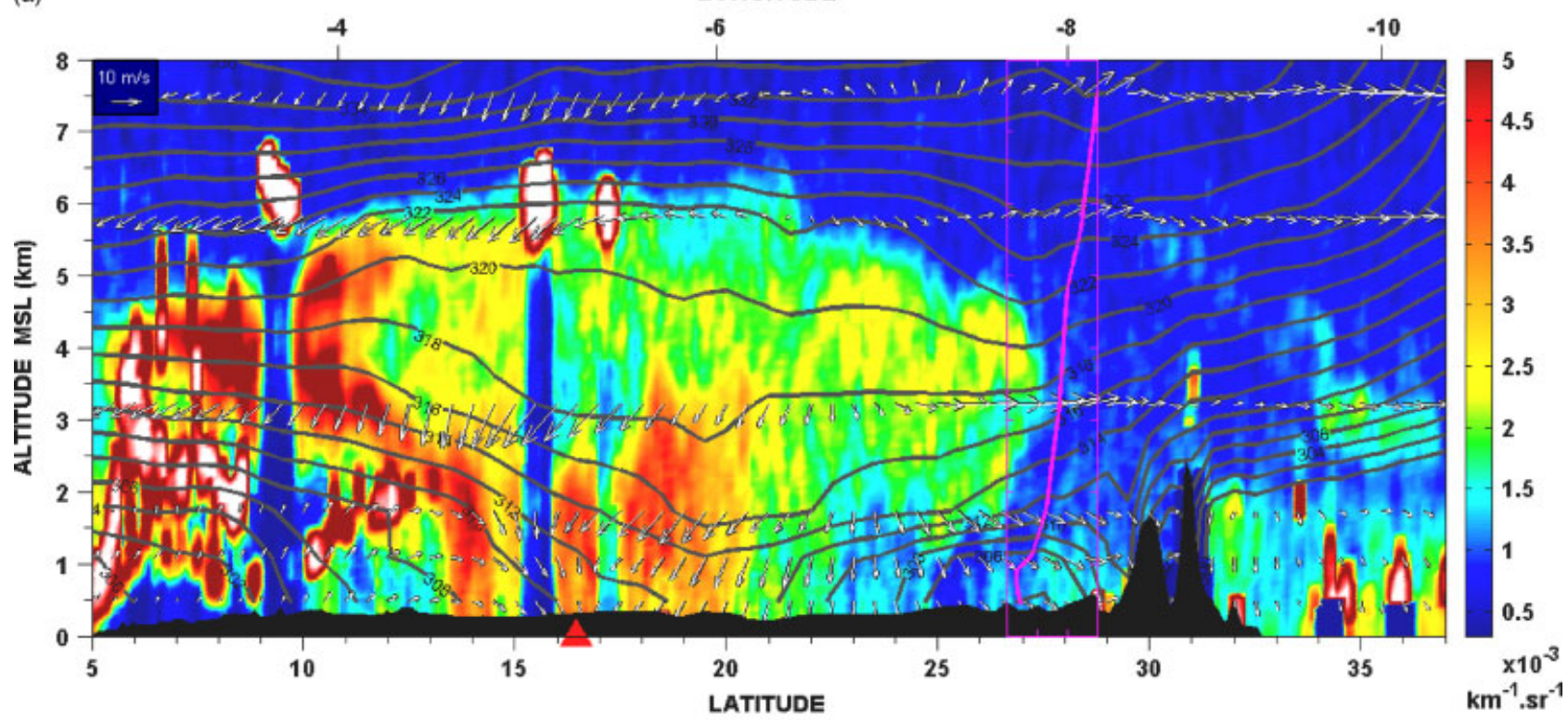

(b)

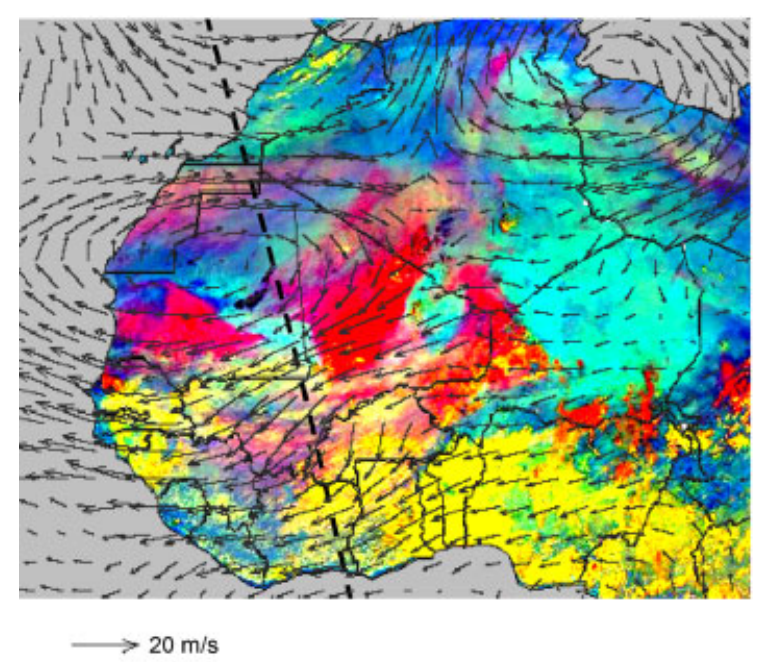

(c)

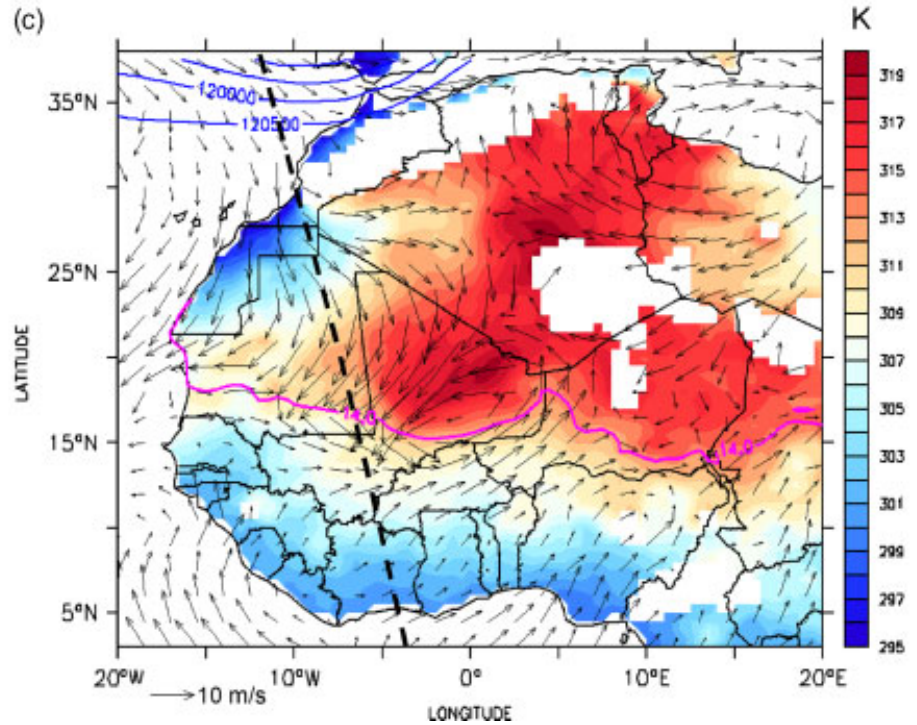

Figure 3. (a) Same as Figure 2(a), but on the 20 June 2007 at 1332 UTC. The radiosounding superimposed (from $300 \mathrm{~K}$ to $330 \mathrm{~K}$ on the horizontal axis) corresponds to Tindouf $\left(27.7^{\circ} \mathrm{N} 8.2^{\circ} \mathrm{W}\right.$ ). (b) SEVIRI image (same as Figure 2(c)) at I330 UTC with ECMWF I 200 UTC winds at $700 \mathrm{hPa}$ superimposed. (c) ECMWF 1200 UTC analysis of potential temperature and winds at $925 \mathrm{hPa}, 14^{\circ} \mathrm{C}$ iso-dew point at the surface in pink and geopotential contours at $200 \mathrm{hPa}$ below $120500 \mathrm{~m}^{2} \mathrm{~s}^{-2}$ in blue. 
In the Sahara, it may lead to exchange of air from the low levels in the SABL to higher levels in the SAL. Using dropsonde data, Parker et al. (2005a) remarked on the occurrence of this mechanism in the vicinity of the inter-tropical discontinuity [(ITD) the near surface convergence zone between the harmattan and the moist monsoon flow coming from the Gulf of Guinea; Hamilton and Archbold, 1945]. This mechanism is particularly effective in transporting southward the dust lifted north of the ITD associated with the downward mixing of the nocturnal low-level jet momentum to the surface during the build-up of the planetary boundary layer in the morning (e.g. Knippertz, 2008). Inversely, but less frequently observed, air in the SAL can be transported down to the SABL lower levels following the slanted isentropes (Parker et al., 2005b). The process of ascent and descent along isentropes was termed 'upgliding' and 'downgliding' by Hoskins et al. (1985).

\subsubsection{Density currents: cold pools and ITD surges}

Cold pool outflows from cumulonimbus convection can lead to dust uplift events, frequently referred to as 'haboobs' (Sutton, 1925). Such events are often associated with mesoscale convective systems (MCSs) over the Sahel in the summer (Hamilton and Archbold, 1945). They may also be triggered by convection over mountainous regions, such as the Atlas (Knippertz and Fink, 2006; Knippertz et al., 2007). Cold pool outflows may be moister or drier than their surroundings (Miller et al., 2008). As they propagate over the Sahara, they rapidly lift up and undercut SABL air masses, which may contain dust. Additionally, turbulence at the leading edge of cold pools is also efficient at lifting dust off the surface (F07). This dust is usually confined to the depth of the cold layer, but has been observed to precede it (Miller et al., 2008) or to mix into the SAL some distances behind the leading edge of the cold pool (F07; Bou Karam et al., 2008). Furthermore, in some instances, the dust lifted by a cold pool was observed to be transported isentropically up to the FT (F07).

The leading edge of the monsoon flow can act as a density current: dust is uplifted by turbulence at the leading edge of the monsoon flow and then lifted isentropically into the SAL (Bou Karam et al., 2008). Airborne data acquired in the framework of Geostationary Earth Radiation Budget Intercomparison of Longwave and Shortwave (GERBILS) Radiation consistently showed high dust loadings within the moist monsoon air in the vicinity of the ITD (e.g. Marsham et al., 2008b). Furthermore, cold pools associated with MCSs have been observed not only to the south of the ITD (Bou Karam et al., 2008), but also to merge with the ITD, thereby favoring the northward advance of the ITD during the day and the lifting of additional erodible material (F07).

\subsection{Topographic effects}

\subsection{Hydraulic jumps downstream of orography}

Previous studies suggest that the vertical structure of the boundary layer may be altered by the occurrence of a hydraulic jump in the lee of an obstacle (e.g. Drobinski et al., 2001), as the result of downslope flow acceleration and downstream abrupt deceleration associated with an increase in the depth of the boundary layer. Such phenomena could occur in presence of a strong harmattan wind impinging on the Hoggar (e.g. Drobinski et al., 2007), as suggested by Figure 4(a), which shows a reduction in the depth of the SABL in the lee of the Hoggar (from $\sim 20.5^{\circ} \mathrm{N}$ to $\sim 23^{\circ} \mathrm{N}$ ) and an abrupt increase of $\sim 1.5 \mathrm{~km}$ further downwind (south of $\sim 20.5^{\circ} \mathrm{N}$ ). The winds along CALIPSO cross-section in Figure 4(a) are mostly aligned with the total north-easterly flow. Total wind speeds shown in Figure 4(b) indicate that the hydraulic jump is well correlated with a strong deceleration of the flow (from $\sim 12 \mathrm{~m} \mathrm{~s}^{-1}$ to $\sim 5 \mathrm{~m} \mathrm{~s}^{-1}$ ) and an increase in vertical velocity, which is coincident with the expansion of the layer. South of the hydraulic jump $\left(20.5^{\circ} \mathrm{N}\right)$, ECMWF vertical speeds suggest strong vertical mixing, as typically associated with the vertical deepening of the boundary layer, which further south seems to have favored the upward mixing of a dust plume that had been lifted the day before at the ITD region (south of $18^{\circ} \mathrm{N}$ ).

Figure 4(c) shows the Froude number $\mathrm{Fr}$ in the SABL that give further evidence of the occurrence of the hydraulic jump at around $\sim 20.5^{\circ} \mathrm{N}$ by a transition from a super-critical (i.e. $F r>1$ ) to a sub-critical flow $(F r<1)$. The Froude number $F r$ is computed as $F r=U / g h \sqrt{\theta_{v} / \Delta \theta_{v}}$ (Drobinski et al., 2001), where $U$ and $\theta_{v}$ are the wind speed and virtual potential temperature in the SABL, $g$ the gravitational acceleration, $h$ the SABL height above ground level and $\Delta \theta_{v}$ the temperature inversion at the SABL top. For $U$ and $\theta_{v}$, we used the ECMWF analysis at $700 \mathrm{hPa}$ $(\sim 3.2 \mathrm{~km} \mathrm{msl})$. We retrieved $h$ from the backscatter profiles and considering a threshold of $20 \%$ of the molecular backscatter coefficient (see dashed black line in Figure 4(a)). The temperature inversion $\Delta \theta_{v}$ was approximated using the Tamanrasset radiosounding at $22.8^{\circ} \mathrm{N}\left(\Delta \theta_{v} \sim 1.2 \mathrm{~K}\right)$ and a range of variability of $\pm 50 \%$ (gray shades) as in Drobinski et al. (2001).

\subsubsection{Flow separation in the lee of the mountains}

Particularly under stable conditions, mountains may induce the separation of the boundary layer into a high-level flow with reduced impact by orography and lower-level reversed flows, stagnant air on the mountain lee and three-dimensional flows around the sides of the mountains (e.g. Scorer, 1955). Figure 5 shows a two-layer structure of the SABL south of the Hoggar mountains, with a clean air layer (up to $1.5 \mathrm{~km}$ above ground level) advected from the east underneath a dust plume (from 1.5 to $4 \mathrm{~km} \mathrm{msl}$ ) originating from 
(a)

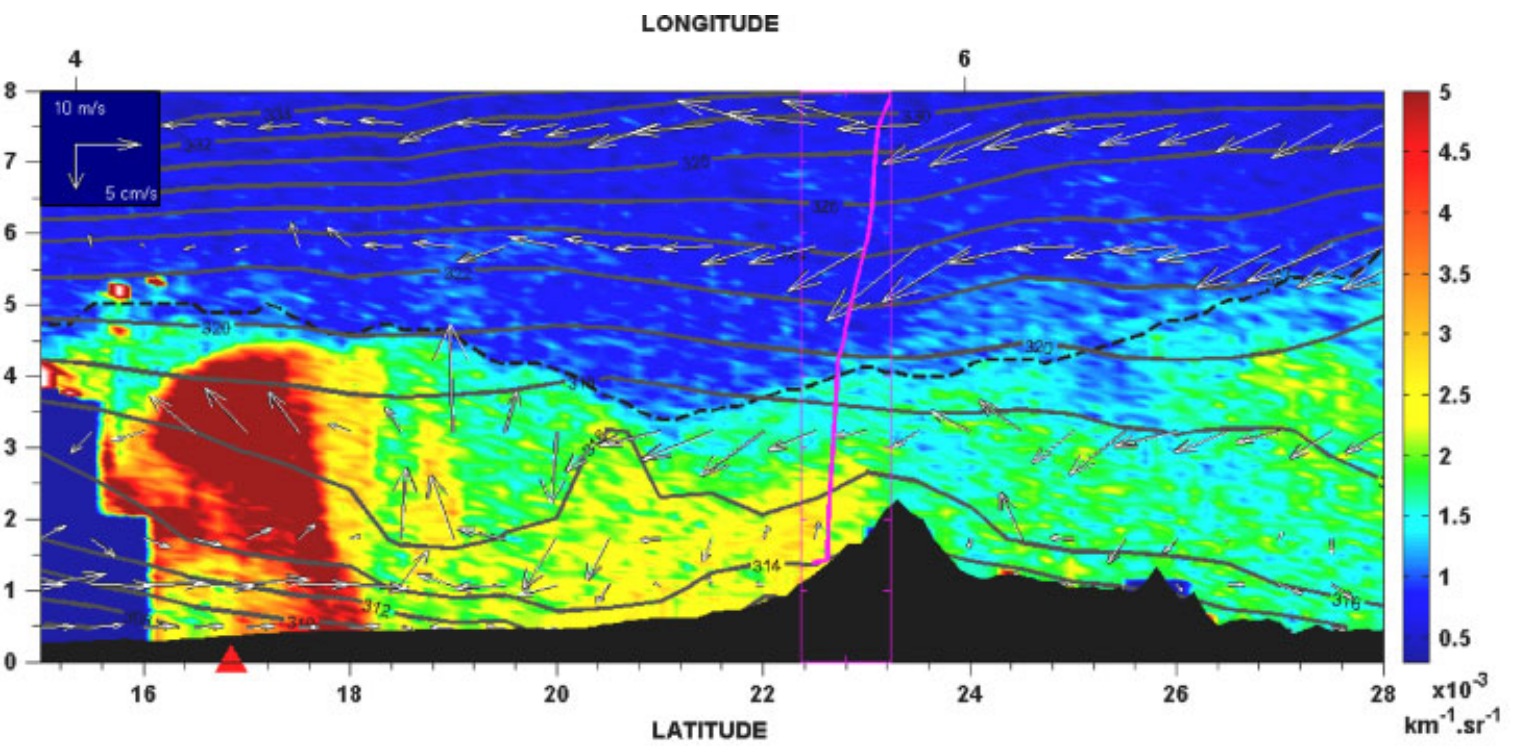

(b)

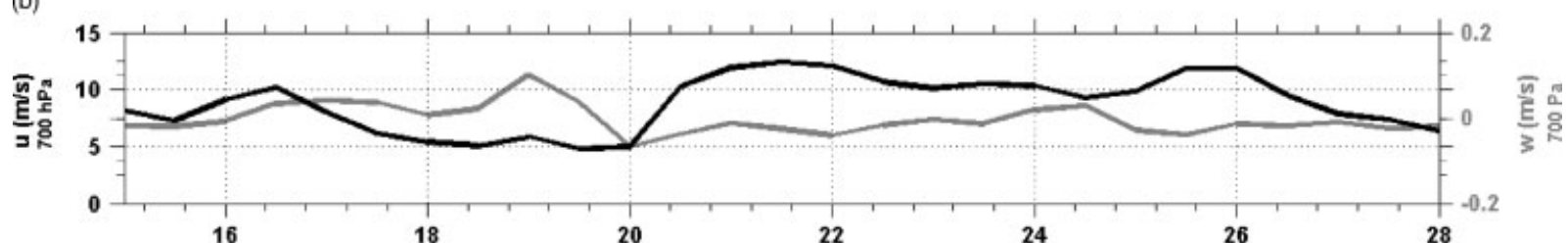

(c)

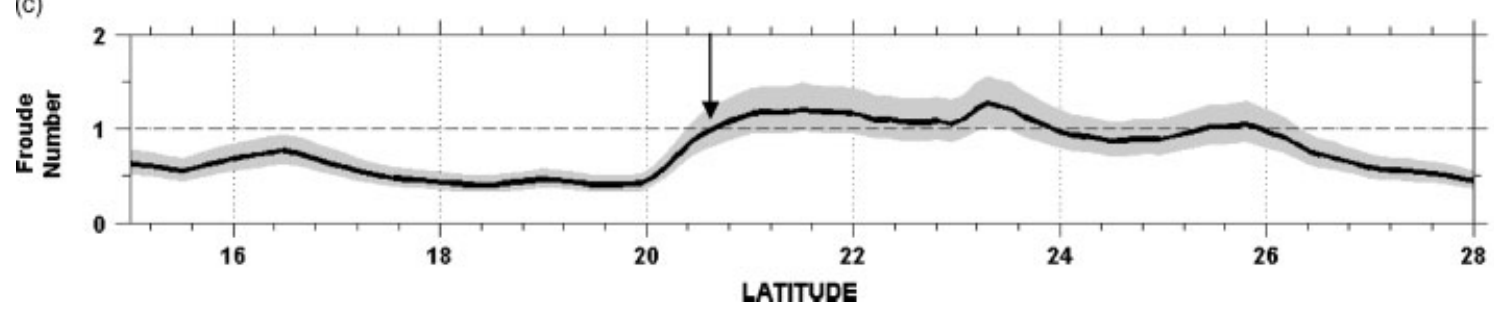

Figure 4. (a) Same as Figure 2(a), but on the I July 2006 at 0137 UTC and arrows represent the flow along CALIPSO cross-section at 0000 UTC (i.e. ECMWF vertical and horizontal components projected along the satellite cross-section). The dashed black line is the SABL top. Tamanrasset virtual temperature profile from the 0000 UTC sounding is superimposed. (b) ECMWF analysis at $700 \mathrm{hPa}$ of horizontal wind speed $u$ (black) and vertical velocities $w$ (gray). (c) Froude number in the SABL. The arrow indicates the hydraulic jump position.

the south. At the higher levels (Figure 5(c)-(d)), a prevailing northerly flow spreads out the dust plume, which is apparent for at least $500 \mathrm{~km}$ south of the Hoggar (reaching $19.5^{\circ} \mathrm{N}$, but obstructed by a cloud at $\sim 22^{\circ} \mathrm{N}$, Figure 5(a)). The differential advection that induces the layering structure is influenced in the vertical and in the horizontal by presence of the Hoggar. The undulating shape of the plume, consistent with the ECMWF vertical velocities, suggests the occurrence of a wave in the lee of the Hoggar, which is above an upslope reversed wind. These features are consistent with Baines (1995), who states that 2D waves and post-wave flow separation are likely to occur as the ratio of height $h$ to along-wind width of the Hoggar is low $(\sim 0.01)$ and a relatively high value $(>2.5)$ of the parameter $N h / U$ indicates a regime propitious to very strong stratification $(N$ is the buoyancy frequency from the Tamanrasset sounding and $U$ the upstream wind speed of $\sim 4 \mathrm{~m} \mathrm{~s}^{-1}$ from the ECMWF analysis). Beneath the dust-laden air, a south-easterly air flow bringing over the much cleaner air masses penetrates almost to the lee of the Hoggar (Figure 5(a)). Figure 5(b) suggests that this airstream originated from an easterly flow that was deflected by the Hoggar and then passed around it.

\subsubsection{Surface albedo 'hot spots'}

The albedo of the land surface in the Sahara is variable, with values from $\sim 0.2$ to 0.55 (Gao et al., 2005). During the day, areas of low albedo lead to positive anomalies in the surface sensible heat flux. If the scale and magnitude of such flux anomalies are sufficiently large and background winds are sufficiently light, circulations will be induced (Segal and Arritt, 1992). An interesting question is whether an ascending hot plume from a 'hotspot' will penetrate up to the SRL, creating subsidence elsewhere in the SRL, and thus tending to suppress the SCBL growth in its vicinity. If the potential temperature of the hot plume is actually 
(a)

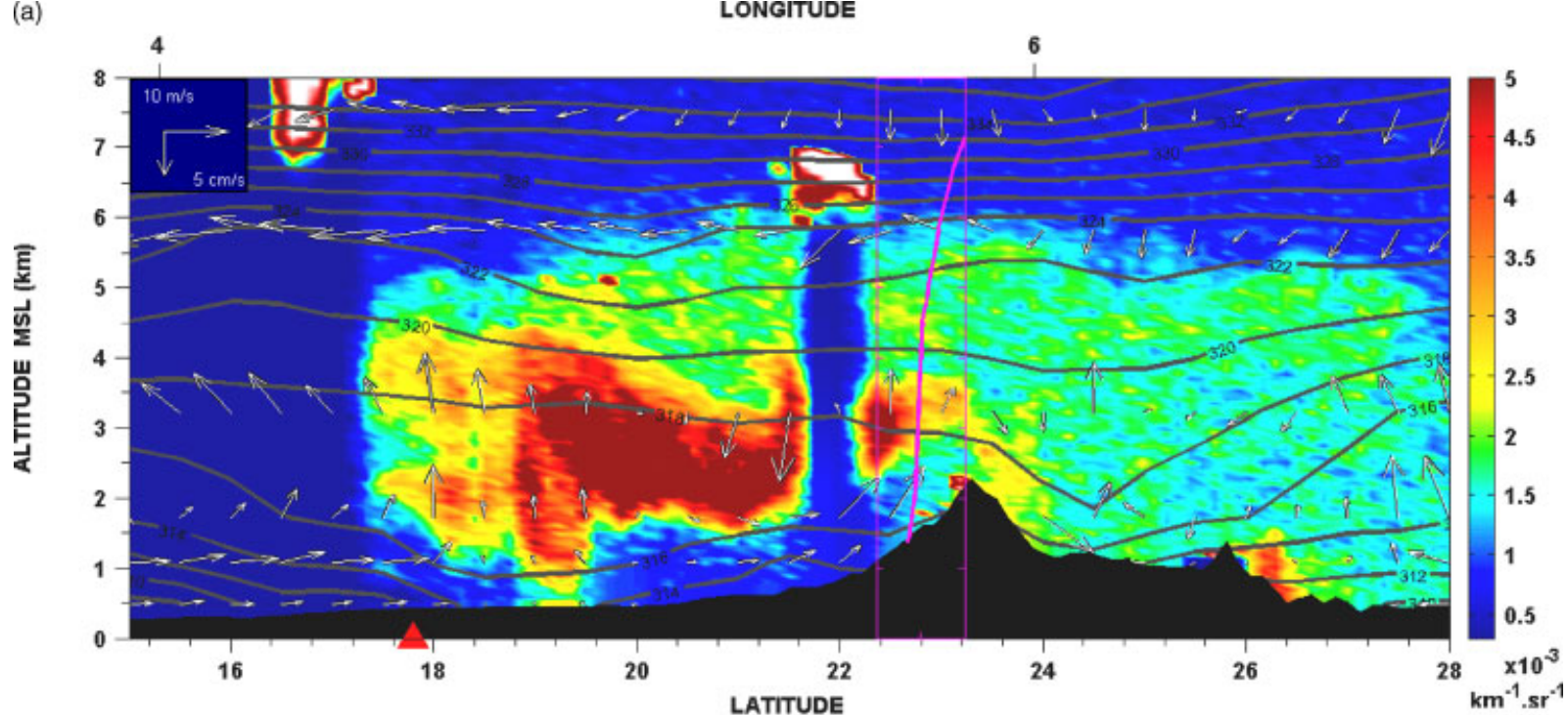

(b)

(c)

(d)

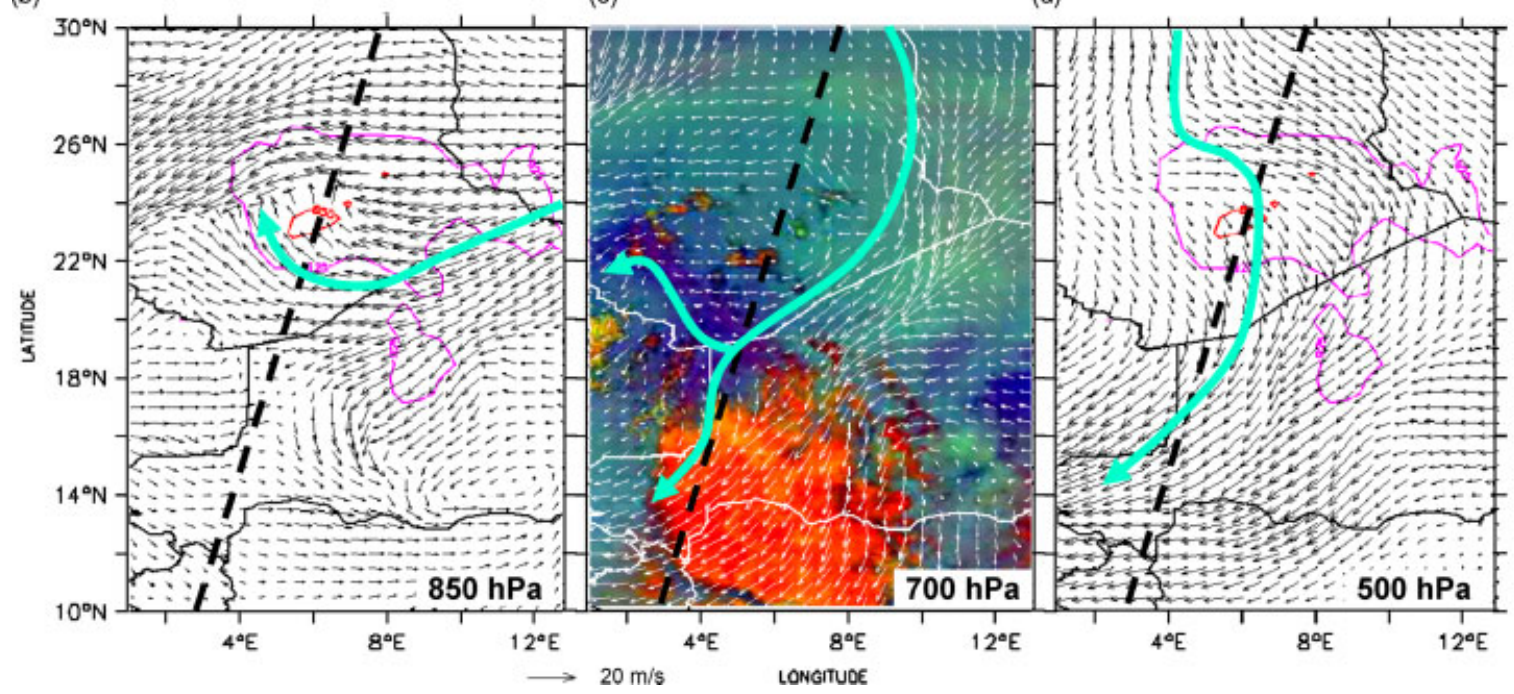

Figure 5. (a) Same as Figure 4(a), but on the 17 July 2006 at 0124 UTC. (b), (c) and (d) show 0000 UTC ECMWF winds at 850 hPa $(\sim 1.6 \mathrm{~km} \mathrm{msl}), 700 \mathrm{hPa}(\sim 3.2 \mathrm{~km} \mathrm{msl})$ and $500 \mathrm{hPa}(\sim 5.8 \mathrm{~km} \mathrm{msl})$ respectively. The SEVIRI image at $0130 \mathrm{UTC}$ is superimposed on winds at approximately the level of the dust plume [700 hPa in (c)]. Contours of the orography exceeding the $925 \mathrm{hPa}$ (pink) and $850 \mathrm{hPa}$ (red) pressure levels are outlined in panels (b) and (d). Light green curves schematically illustrate the paths of the air masses arriving at the transect zone.

warmer than the SRL, this will stabilise the SRL with respect to the SCBL.

Using data from two long aircraft legs flown in the SCBL, Marsham et al. (2008a) showed that, on scales of $\sim 10 \mathrm{~km}$ or more, a significant coupling existed between land surface temperatures, SCBL virtual potential temperatures and along-track SCBL winds. As expected, this coupling was observed to decrease with increasing wind speeds in the boundary layer. However, Marsham et al. (2008a) could not describe the impacts on the SRL because for their case observations were only available from the SCBL.

Figure 2 shows a possible impact of an albedo anomaly (0.2 compared with 0.4 elsewhere) that is manifested as the formation of a cloud at the top of the SABL, at around $\sim 17^{\circ} \mathrm{N}$ (Figure $2(\mathrm{a})-(\mathrm{c})$ ). ECMWF analysis barely resolves this feature, but does show ascending winds under this cloud (up to $\sim 15 \mathrm{~cm} \mathrm{~s}^{-1}$ at $\left.1800 \mathrm{UTC}\right)$ when all other conditions (ECMWF water vapor mixing ratio, horizontal wind direction, ground elevation, etc; Figure 2(d)) were not significantly different from the surrounding areas. The presence of this cloud at the top of a local deepening in the SABL therefore supports the hypothesis of Marsham et al. (2008a) that such albedo features can lead to locally deeper convection and exchange between the SCBL and above.

\subsubsection{Orographic 'hot spots'}

By inspection of ECMWF vertical velocity fields and airborne observations, Flamant et al. (F07) postulated that dry convective ascent driven by elevated heating over the Atlas mountains forced subsidence over the Sahara. On the northern side of the Sahara, the Atlas mountains rise to $4000 \mathrm{~m} \mathrm{msl}$, while in 
the centre of the desert the Hoggar reaches nearly $3000 \mathrm{~m} \mathrm{msl}$; these altitudes being comparable with the depth of the SCBL during the morning hours (C08), so that the mountain tops are inside the SRL in the first hours after sunrise. Therefore it is quite likely that elevated heating over these mountain ranges leads to plumes of hot air which penetrate into the SRL, increasing its temperature in the vicinity of the mountains, and suppressing the SCBL growth elsewhere, through stabilisation of the profile and large scale compensating subsidence. On the mesoscale, even low hills will generate a plume of hot, rising air - known as a 'convective core' - when winds are sufficiently light (Tian and Parker, 2002).

\section{Discussion and conclusions}

The stratification of the SABL during the day, into a SRL and SCBL, has implications for the thermodynamics over the Sahara, and for the transport of atmospheric constituents, notably mineral dust. In some cases, dust which is lifted at the surface by strong winds is confined in a relatively shallow SCBL, beneath a deeper SRL. Later in the day, this dusty SCBL grows to fill the SABL. In some other times and locations, dust is elevated relatively quickly into the SRL. In the SRL, turbulence is relatively low, or minimal, and the air can be advected relatively rapidly. This stratified state with a dust layer above a relatively clear SCBL is a relatively common observation. In most cases, it becomes fully mixed by late afternoon. The relative importance and locations of these two situations is still to be demonstrated through extended observations and modeling.

This paper presents a set of dynamical mechanisms by which air is exchanged vertically within the SABL, between the SCBL and SRL. These dynamical mechanisms (Figure 1) have been reported in previous work, but at this stage we are not able to evaluate the relative importance of each. Diurnal mixing (3.1), cold air outbreaks (3.2.1) and density currents (3.2.2) have been studied thoroughly on the basis of observations made in the framework of recent field campaigns (e.g. SAMUM, AMMA, GERBILS), although their climatological significance and representativity has not been analyzed yet. The role of the albedo (3.3.3) and orographic (3.3.4) hot spots on vertical mixing within the SABL, as well as isentropic upgliding (3.2.1), are mostly hypothesized and still need to be demonstrated thoroughly through case studies and modeling. Other orographic effects such as hydraulic jumps (3.3.1) and flow separation (3.3.2) have been mostly documented in other regions and their role in the Sahara is still to be better studied. Moreover, the occurrence of hybrid cases (e.g. a mountain with an albedo anomaly) as well as the interaction between these mechanisms should be taken into account in future analyses.

Boundary-layer schemes used in global models are not designed for such deep and complex desert boundary layers. Gamo (1996) showed that the lapse rates over deserts tend to be closer to neutral than in the ECMWF global model and that the ability of global models to represent SABL processes should be further evaluated.

The AMMA, SAMUM and GERBILS observational programmes have taken us, in the space of a few years, from having very few data over the Sahara to having some high quality datasets from local sites and aircraft or satellite case-studies. The next steps in progress must be to use these datasets in order to qualify model-based climatologies. As part of this analysis, we need to develop an understanding of the coherence of the SABL, remote from the SAMUM and AMMA ground sites. In that case, particular interest is addressed to the SABL diurnal cycle, without the influence of orography and in proximity of the Saharan Heat Low.

\section{Acknowledgements}

'Based on a French initiative, AMMA was built by an international scientific group and is currently funded by a large number of agencies, especially from France, UK, US and Africa. It has been the beneficiary of a major financial contribution from the European Community's Sixth Framework Research Programme. See http://www.ammainternational.org'. We thank Andrew Ross for fruitful discussions regarding orographic flows. The authors would like to thank K. Ramage and S. Cloché (Institut Pierre Simon Laplace, France) for facilitating access to ECMWF and CALIPSO data, as well as L. Gonzalez and C. Deroo (Laboratoire d'Optique Atmosphérique) for supplying the SEVIRI composite images. We would also like to thank two anonymous reviewers whose comments significantly improved the clarity of the paper.

\section{References}

Baines PG. 1995. Topographic Effects in Stratified Flows. Cambridge University Press: Cambridge, UK; pp. 498.

Bou Karam D, Flamant C, Knippertz P, Reitebuch O, Pelon J, Chong M, Dabas A. 2008. Dust emissions over the Sahel associated with the West African Monsoon inter-tropical discontinuity region: a representative case study. Quarterly Journal of the Royal Meteorological Society 134: 621-634.

Cakmur RV, Miller RL, Torres O. 2004. Incorporating the effect of small-scale circulations upon dust emission in an atmospheric general circulation model. Journal of Geophysical Research 109: D07201, DOI:10.1029/2003JD004067.

Cattrall C, Reagan J, Thome K, Dubovik O. 2005. Variability of aerosol and spectral lidar and backscatter and extinction ratios of key aerosol types derived from selected Aerosol Robotic Network locations. Journal of Geophysical Research 110: D10S11, DOI:10.1029/2004JD005124.

Chaboureau J-P, Tulet P, Mari C. 2007. Diurnal cycle of dust and cirrus over West Africa as seen from Meteosat Second Generation satellite and a regional forecast model. Geophysical Research Letters 34: L02822, DOI:10.1029/2006GL027771.

Cuesta J, Edouart D, Mimouni M, Flamant PH, Loth C, Gibert F, Marnas F, Bouklila A, Kharef M, Ouchene B, Kadi M, Flamant C. 2008. Multi-platform observations of the seasonal evolution of the Saharan atmospheric boundary layer in Tamanrasset, Algeria, in the framework of the African Monsoon Multidisciplinary Analysis field campaign conducted in 2006. Journal of Geophysical Research 113: D00C07, DOI:10.1029/2007JD009417. 
Drobinski P, Bastin S, Janicot S, Dabas A, Delville P, Denneullin ML, Nagel E, Reitebuch O, Romand B. 2007. Role of scale interactions and orography on the late northward propagation of the West African monsoon in summer 2006 in the region of Niger/Mali. In AMMA 2th International Conference, Karlsruhe, 26-30 Nov. 2007.

Drobinski P, Flamant C, Dusek J, Flamant PH, Pelon J. 2001. Observational evidence and modeling of an internal hydraulic jump at the atmospheric boundary layer top during a Tramontane event. Boundary-Layer Meteorology 98: 497-515.

Engelstaedter S, Tegen I, Washington R. 2006. North African dust emissions and transport. Earth-Science Reviews 79: 73-100.

Fernald FG, Herman BM, Reagan JA. 1972. Determination of aerosol height distributions by lidar. Journal of Atmospheric Meteorology 11: $482-489$.

Flamant C, Chaboureau JP, Parker DJ, Taylor CM, Cammas JP, Bock O, Timouk F, Pelon J. 2007. Airborne observations of the impact of a convective system on the planetary boundary layer thermodynamics and aerosol distribution in the inter-tropical discontinuity region of the West African Monsoon. Quarterly Journal of the Royal Meteorological Society 133: 1175-1189.

Gamo M. 1996. Thickness of the dry convection and large-scale subsidence above deserts. Boundary-Layer Meteorology 79(3): 265-278.

Gao F, Scaaf CB, Strahler AH, Roesch A, Lucht W, Dickinson R. 2005. MODIS bidirectional reflectance distribution function and albedo Climate Modeling Grid products and the variability of albedo for major global vegetation types. Journal of Geophysical Research 110: D01104, DOI:10.1029/2004JD005190.

Hamilton RA, Archbold JW. 1945. Meteorology of Nigeria and adjacent territory. Quarterly Journal of the Royal Meteorological Society 71: 231-264.

Hoskins BJ, McIntyre ME, Robsertson AW. 1985. On the use and significance of isentropic potential vorticity maps. Quarterly Journal of the Royal Meteorological Society 111: 877-946.

Karyampudi VM, Carlson TN. 1988. Analysis and numerical simulations of the saharan air layer and its effect on easterly wave disturbances. Journal of the Atmospheric Sciences 45(21): 3102-3136.

Knippertz P. 2008. Dust emissions in the West African heat trough - the role of the diurnal cycle and of extratropical disturbances. Meteorologische Zeitschrift 17(5): 553-563, DOI 10.1127/0941-2948/2008/0315.

Knippertz P, Ansmann A, Althausen D, Müller D, Tesche M, Bierwirth E, Dinter T, Müller T, von Hoyningen-Huene W, Schepanski K, Wendisch M, Heinold B, Kandler K, Petzold A, Schültz L, Tegen I. 2008. Dust mobilization and transport in the northern Sahara during SAMUM - A meteorological overview. Tellus B In press. DOI:10.1111/j.1600-0889.2008.00380.x.

Knippertz P, Deutscher C, Kandler K, Müller T, Schulz O, Schütz L. 2007. Dust mobilization due to density currents in the Atlas region: Observations from the Saharan Mineral Dust Experiment 2006 field campaign. Journal of Geophysical Research 112: D21109, DOI:10.1029/2007JD0087741.

Knippertz P, Fink AH. 2006. Synoptic and dynamic aspects of an extreme springtime Saharan dust outbreak. Quarterly Journal of the Royal Meteorological Society 132: 1153-1177.

Koch J, Renno NO. 2005. The role of convective plumes and vortices on the global aerosol budget. Geophysical Research Letters 32(18): L18806 (1-5), DOI: 10.1029/2005GL023420.

Marsham JH, Parker DJ, Grams CM, Johnson BT, Grey WMF, Ross AN. 2008a. Observations of mesoscale and boundary-layer scale circulations affecting dust transport and uplift over the Sahara. Atmospheric Chemistry and Physics 8: 6979-6993.

Marsham JH, Parker DJ, Grams CM, Taylor CM, Haywood JM. 2008b. Uplift of Saharan dust south of the inter-tropical discontinuity (ITD). Journal of Geophysical Research 113: D21102, DOI:10.1029/2008 JD009844.

Miller SD, Kuciauskas AP, Liu M, Ji Q, Reid JS, Breed DW, Walker AL, Mandoos AA. 2008. Haboob dust storms of the southern Arabian Peninsula. Journal of Geophysical Research 113: D01202, DOI:10.1029/2007JD008550.

N'Tchayi Mbourou G, Bertrand JJ, Nicholson SE. 1997. The diurnal and seasonal cycles of wind-borne dust over Africa north of the equator. Journal of Applied Meteorology 36: 868-882.

Parker DJ. 2002. The response of CAPE and CIN to tropospheric thermal variations. Quarterly Journal of the Royal Meteorological Society 128: 119-130.

Parker DJ, Burton RR, Diongue-Niang A, Ellis RJ, Felton M, Taylor CM, Thorncroft CD, Bessemoulin P, Tomkins AM. 2005a. The diurnal cycle of the West African monsoon circulation. Quarterly Journal of the Royal Meteorological Society 131: 2839-2860.

Parker DJ, Thorncroft CD, Burton RR, Diongue-Niang A. 2005 b. Analysis of the African easterly jet, using aircraft observations from the JET2000 experiment. Quarterly Journal of the Royal Meteorological Society 131: 1461-1482.

Reid J, Westphal D, Livingston J, Savoie D, Maring H, Jonsson H, Eleuterio D, Kinney J, Reid E. 2002. Dust vertical distribution in the Caribbean during the Puerto Rico Dust experiment. Geophysical Research Letters 29(7): 1151, DOI 10.1029/2001GL014092.

Scorer RS. 1955. The theory of airflow over mountains - IV. Separation of flow from the surface. Quarterly Journal of the Royal Meteorological Society 81: 340-350.

Segal M, Arritt RW. 1992. Nonclassical mesoscale circulations caused by surface sensible heat-flux gradients. Bulletin of the American Meteorological Society 73(10): 1593-1604.

Shao Y. 2000. Physics and Modelling of Wind Erosion. Kluwer Academic: Norwell, MA; 391.

Sterk G. 2002. Causes, consequences and control of wind erosion in Sahelian Africa: a review Land Degradation \& Development. Land Degradation \& Development 14(1): 95-108, DOI: 10.1002/ldr.526.

Sutton II. 1925. Haboobs. Quarterly Journal of the Royal Meteorological Society 51: 25-50.

Tanaka TY, Chiba M. 2006. A numerical study of the contributions of dust source regions to the global dust budget. Global and Planetary Change 52(104): 88-104.

Tian WS, Parker DJ. 2002. Two-dimensional simulation of orographic effects on mesoscale boundary-layer convection. Quarterly Journal of the Royal Meteorological Society 128: 1929-1952.

Washington R, Todd MC, Engelstaedter S, Mbainayel S, Mitchell F. 2006. Dust and the low-level circulation over the Bodélé Depression, Chad: Observations from BoDEx 2005. Journal of Geophysical Research 111: D03201, DOI:10.1029/2005JD006502.

Winker DM, Hunt WH, McGill MJ. 2007. Initial performance assessment of CALIOP. Geophysical Research Letters 34: L19803, DOI: 10.1029/2007GL030135.

Young S, Winker D, Vaughan M, Hu Y, Kuehn R. 2008. Extinction Retrieval Algorithms, CALIOP algorithm theoretical basis document PC-SCI-202 Part 4, Available on http://www-calipso.larc.nasa.gov/ resources/pdfs/PC-SCI-202_Part4_v1.0.pdf. 